\title{
DIREITO À COMUNICAÇÃO NA WEB: INTERESSE PÚBLICO E DIREITOS SOCIAIS NA PAUTA DO PORTAL COMUNITÁRIO
}

\author{
COMMUNICATION RIGHT ON THE \\ WEB: PUBLIC INTEREST AND \\ SOCIAL RIGHTS ON THE AGENDA \\ OF PORTAL COMUNITÁRIO
}

\author{
Aline Czezacki Kravutschke* \\ Karina Janz Woitowicz ${ }^{* *}$ \\ Volney Campos dos Santos ${ }^{* * *}$
}

\section{RESUMO}

O artigo objetiva discutir o direito à comunicação como parte das práticas de cidadania, a partir da experiência do site jornalístico Portal Comunitário, criado em 2008 na Universidade Estadual de Ponta Grossa, que busca dar visibilidade às demandas de mais de 50 entidades da sociedade civil. 0 texto parte da fundamentação teórica sobre jornalismo comunitário e cidadania para caracterizar a experiência na produção de conteúdos e a participação popular no site. Para tanto, traz levantamentos quantitativos referentes à cobertura jornalística, identificando dados sobre as produções nos bairros e os temas mais relevantes tratados no portal, que indicam o modo como o interesse público pauta a prática jornalística, além de apresentar dados sobre a seção "Espaç̧o Jurídico", que oferece orientação sobre direitos e oportuniza a participação dos cidadãos. Com esta abordagem, o trabalho apresenta aspectos do jornalismo comunitário em tempos de expansão das mídias digitais, revelando a importância de dar visibilidade às demandas comunitárias e incentivar a participação popular no fortalecimento da cidadania.

Palavras-chave: Direito à comunicação; jornalismo comunitário; cidadania; extensão universitária.

\section{ABSTRACT}

This paper aims at discussing the communication right as part of the citizenship practices, from the experience of the journalistic website Portal Comunitário, created in 2008 at the State University of Ponta Grossa, which seeks to bring visibility to the demands of over 50 civil society organizations. The text begins with the theoretical background for community journalism and citizenship to characterize the experience

\footnotetext{
* Repórter do Ministério da Saúde. E-mail: alineczezacki@gmail.com

** Professora da Universidade Estadual de Ponta Grossa (UEPG), PR - Brasil. E-mail: karinajw@gmail.com

*** Professor da Universidade Estadual de Ponta Grossa (UEPG), PR - Brasil. Aluno de Doutorado da Universidade Estadual de Ponta Grossa (UEPG), PR - Brasil. E-mail: volneycs@gmail.com
} 
in content production and popular participation in the site. For this purpose, it brings quantitative surveys relating to news coverage, identifying data on productions in the neighborhoods of the city and the most relevant topics treated in the portal, which indicate how the public interest appears in the journalism practice. It also presents data on the "Espaço Jurídico", a section which offers guidance on rights and favors the participation of citizens. With this approach, the paper presents aspects of community journalism in times of expansion of digital media, revealing the importance of giving visibility to community needs and encourage popular participation to strengthen citizenship.

Keywords: communication right; community journalism; citizenship; university extension.

\section{Introdução}

Discutir a perspectiva da comunicação comunitária sob o viés do direito à comunicação e à cidadania, a partir da experiência do site jornalístico Portal Comunitário ${ }^{1}$, projeto de extensão criado em 2008 na Universidade Estadual de Ponta Grossa (Paraná/Brasil). Este é o propósito do presente artigo, que parte de uma reflexão sobre o direito à comunicação para fundamentar a prática do jornalismo comunitário, que tem como princípios a participação popular e a reivindicação de demandas sociais.

O Portal Comunitário é um site que articula produção jornalística e prestação de serviços dentro dos princípios da comunicação comunitária, por meio de um trabalho que integra ação extensionista (de professores e alunos da universidade) e participaçáo da comunidade, com parcerias com entidades da sociedade civil.

Entende-se que a comunicação comunitária pressupõe a participação dos cidadãos e a valorização da cidadania. ${ }^{2}$ Neste sentido, está entre os propósitos do Portal Comunitário fortalecer o diálogo com as entidades da sociedade civil, estabelecendo a mediação entre a produção noticiosa e as açóes dos grupos e entidades de Ponta Grossa.

O projeto contempla, atualmente, mais de 50 entidades da sociedade civil do município, entre ONGs e grupos, movimentos sociais, associaçóes de moradores e sindicatos. Ao longo de oito anos de trajetória, pode-se dizer que o projeto, apesar das limitaçóes próprias de uma iniciativa extensionista no âmbito de uma Universidade pública, se fortaleceu tanto no que diz respeito à perspectiva da comunicação comunitária e da participação cidadã quanto em relação à sua estrutura técnica, formato e linguagem, resultando em uma produção jornalística que valoriza o local e tematiza as açóes e reivindicaçóes de bairros, sindicatos, movimentos sociais e entidades de Ponta Grossa/PR.

Para caracterizar a experiência do Portal Comunitário no campo da comunicação comunitária, serão trazidas no artigo algumas reflexóes teóricas sobre jornalismo, cidadania e direito à comunicação, bem como dados resultantes de levantamento junto ao banco de dados do projeto, que indicam a presença de temas de relevância social na cobertura noticiosa do site.

$\mathrm{O}$ artigo aborda especificamente um espaço em que se dá uma intensa participação da comunidade local, seja por meio de comentários ou de questionamentos sobre temas diversos: o Espaço Jurídico. A sessão presta um trabalho de orientação jurídica aos leitores, fortalecendo a característica de prestação de serviço que identifica a linha editorial do site.

\footnotetext{
1 Disponível em: http://www.portalcomunitario.jor.br.

2 Entende-se por cidadania a inclusão das pessoas na esfera pública, tanto como sujeitos ativos na definição dessa esfera enquanto espaço institucional de participação política, mas principalmente pela participação direta no debate público, como atores produtores de si mesmos e como credores do estado e da sociedade em termos de liberdades, bens e direitos. Cf. FALEIROS, Vicente de Paula. Cidadania e política. In: LUIZ, Danuta Cantóia. Sociedade civil e democracia: expressões contemporâneas. São Paulo: Veras Editora, 2010.
} 
Por meio desta abordagem, o trabalho apresenta aspectos do jornalismo comunitário em tempos de expansão das mídias digitais, revelando a importância de dar visibilidade às demandas locais no fortalecimento do direito à comunicação como parte das lutas pela cidadania.

\section{Cidadania e direito à comunicaçáo}

É inegável a relaçáo direta entre democracia e comunicação social. Pressuposto fundamental para a construçáo de um modelo de sociedade democrática é o conhecimento das posiçóes políticas e valores sociais que são objeto do debate. No estágio atual da vida em sociedade, a forma de funcionamento dos meios de comunicaçáo pode determinar se o sistema político e social reflete efetivamente os interesses dos diversos grupos ou se representa a ratificaçáo da posiçấo dos interesses dos que dominam os meios (SANTOS, 2006).

Apesar de existir uma longa tradição brasileira acerca da liberdade de expressão, liberdade de imprensa e direito à informaçáo, aos poucos surge nos bastidores jurídicos e nas lutas da sociedade civil a construção de um direito à comunicação, propondo um debate crítico sobre o uso dos meios de comunicaçáo e o reconhecimento do direito à comunicação como um direito humano (SANTOS, 2006).

$\mathrm{O}$ debate acerca do direito à comunicação e seu reconhecimento náo é novo. Desde há muito, produtores da comunicação, sobretudo aqueles que se preocupam com a concentração dos meios de comunicação em mãos de grandes corporaçôes, reivindicam o direito humano a receber, produzir e divulgar uma informaçáo veraz e oportuna (BRAZ, 2011).

Ainda segundo o autor, as tecnologias da informação e da comunicaçáo tornaramse ferramentas essenciais na busca por consenso e adesão a determinadas ideias, o que significa afirmar que os meios de comunicação assumiram um papel central na disputa política e na luta por direitos.

Porém, os altos investimentos envolvidos no desenvolvimento e aquisiçáo dessas tecnologias faz com que a produçáo e divulgaçáo da informaçáo passem a estar concentradas nas mãos de alguns poucos conglomerados de mídia, gerando um processo de filtragem e direcionamento na formação do conceito de interesse público que orientará o processo de tomada de decisão da sociedade (BRAZ, 2011). Assim, a suposta igualdade de direitos é prejudicada pelas desigualdades nas relaçóes de poder.

Há uma restriçáo, portanto, ao acesso à informação veraz e oportuna, fazendo com que a liberdade de expressão e o direito igualitário à informação não se apresentem como prática efetiva. Contudo, diante das experiências de comunicaçáo comunitária, popular e alternativa, identifica-se um campo de produção e circulação de conteúdos que descentraliza os fluxos comunicacionais e propóe formas diferenciadas e participativas de atuaçáo na esfera pública, aproximando-se de uma perspectiva de exercício da cidadania que contribui para o fortalecimento da democracia.

É pertinente considerar que o conceito de jornalismo comunitárioº , que dá base aos estudos e reflexóes dos fenômenos que envolvem as formas alternativas de produçáo

3 Os termos 'comunicação comunitária', 'comunicação popular', 'mídia cidadã', 'mídia alternativa', entre outras variações, são tratados neste texto como um conjunto de práticas que, embora apresentem conceituação 
midiática, foi se consolidando a partir das contribuiçóes de pesquisadores que partiram do caráter participativo das experiências de comunicação. No Brasil, os estudos em comunicação comunitária e popular, em sintonia com a realidade dos países da América Latina ${ }^{4}$, convergem em preocupaçóes que se baseiam na articulaçáo entre as experiências de comunicaçáo e as expressóes da cultura popular e dos movimentos de resistência. A partir dos anos 1960, há uma série de experiências de comunicação, de caráter popular, que configuram um cenário em que a mídia era pensada pelo seu papel educativo, reivindicatório e mobilizador.

Nos últimos 20 anos, o interesse pela comunicaçáo comunitária ganhou relevo no meio acadêmico, acompanhando o fortalecimento de experiências de rádio e TV comunitária, o uso da internet como mídia contra-hegemônica e o desenvolvimento de práticas de comunicaçáo protagonizadas pelos novos movimentos sociais e pelo terceiro setor.

O jornalismo comunitário, conforme Raquel Paiva (1998), propõe um modo de comunicação que admite a participação direta dos cidadãos e cidadấs no processo de produção e visa a politizaçáo e a organizaçáo das comunidades. No que diz respeito ao perfil dos veículos comunitários, pode-se destacar, a partir de Paiva (1998), o uso didático e educativo, de interesse público, a valorização do local, o caráter de prestação de serviços, com proposta social, o objetivo de mobilização e transformação, a participação coletiva e o uso dos meios como facilitadores de um processo de emancipaçáo cidadã.

Na perspectiva de Armand Mattelart (2009), os direitos relacionados à comunicação se entrelaçam com os direitos culturais e coletivos e com o direito de participaçáo.

Os direitos da Comunicação não incluem apenas a comunicação na esfera pública (liberdade de expressão, de imprensa, o acesso à informação pública e governamental, a diversidade e a pluralidade dos meios de comunicaçáo e dos conteúdos). Eles abrangem a produção e o compartilhamento de conhecimentos; os direitos civis, como a privacidade; os direitos culturais, como a diversidade linguística. (MATTELART, 2009, p. 43)

Com base nesta perspectiva de atuaçáo jornalística vinculada ao princípio de inclusão dos grupos sociais, entende-se que a defesa do direito de comunicar como parte das lutas pela cidadania constitui atualmente o ponto de partida para os estudos na área. Este aspecto pode ser confirmado a partir da preocupaçáo com o desenvolvimento de políticas democráticas de comunicação, que não apenas garantam o acesso a uma informação plural, mas também oportunizem a produção de conteúdos, conforme enunciado na Carta de Sáo Bernardo do Campo, resultante do Seminário WACC/

própria, remetem às formas de comunicação que se relacionam com as práticas de cidadania. Portanto, não é objetivo deste trabalho debater as diferenciações e especificidades de tais conceitos.

4 Nos países da América Latina, a relação entre a comunicação e os movimentos populares dá sustentação aos estudos na área: Luis Ramiro Beltrán (1981) parte da contraposição entre comunicação vertical/antidemocrática e horizontal/democrática para discutir as experiências de comunicação popular e alternativa. Fernando Reyes Matta (1983) sustenta que uma "outra" comunicação depende do grau de inserção destas práticas nos movimentos populares, de forma orgânica, sendo capazes de criar a identidade do movimento social a partir de seus próprios protagonistas. Mario Kaplun (1996), por sua vez, refere-se aos meios de comunicação como instrumentos de educação popular, destacando a importância dos veículos nas etapas de conhecimento da realidade, formulação crítica e estímulo à participação coletiva. E Massimo Grinberg (1987) observa que a comunicação alternativa surge para gerar mensagens com concepções diferentes ou opostas às difundidas pelos meios dominantes, apresentando uma diferença qualitativa em relação aos meios hegemônicos, a partir de seus conteúdos. 
UNESCO/Metodista de Mídia Cidadã realizado em 2005. De acordo com Gobbi (2006, p. 243-244),

Reafirmamos que o princípio da comunicação como direito humano fundamental pressupóe não somente o acesso, mas a construção de conteúdos, a apropriação da tecnologia e a multiplicação da diversidade cultural e da socialização do conhecimento, contemplando políticas públicas de proteção dos conteúdos locais/regionais/nacionais e das indústrias criativas.

Ao questionar "quem de fato tem o direito de se expressar através da mídia" (PERUZZO, 2004, p. 66), os movimentos criaram meios próprios de expressão (comunicação comunitária, popular ou alternativa) e também partiram para a discussão sobre a democratização da mídia, principalmente sobre a concessão pública de emissoras de rádio e TV, reivindicando acesso a esses meios para as organizaçóes populares, conquistando o que hoje são as rádios e TVs comunitárias, mas também cobrando maior clareza, transparência e controle social sobre todas as concessóes. A inserção de movimentos sociais e demais entidades da sociedade civil organizada na internet também é outra demanda de discussão, uma vez que a web possibilita a construção de canais próprios de comunicação - como blogs, sites e participação em redes sociais - que independem do controle hegemônico da mídia.

Rousiley Maia (2006) discute a relação entre as novas tecnologias da informação e da comunicação e o processo democrático, considerando que as redes eletrônicas permitem que as pessoas interajam localmente ou globalmente, assumindo potencial de participação na esfera pública. Contudo, deve-se considerar as assimetrias entre 'incluídos' e 'excluídos' das tecnologias da informação (MORAES, 2007) e ter presente que os meios, por si só, náo garantem a participação nos processos sociais.

$\mathrm{Na}$ análise de Maia (2008, p. 292),

Muitas das práticas comunicativas que acontecem nos contextos socioculturais da vida diária e nas esferas públicas periféricas não alcançam as instâncias formais do sistema político. Permanecem sem expressão política e, consequentemente, sem eficácia política. Contudo, no quadro da sociedade em rede, com as novas tecnologias da informação e da comunicação, que ultrapassam a perspectiva dos meios massivos e o monopólio da informaçấo, os processos conversacionais e de aprendizagem social devem ser seriamente considerados. O processo discursivo e a negociação de interesses, por meio de práticas comunicativas com maior ou menor grau de formalidade, acontecem dentro de um campo de oportunidades e constrangimentos.

Barbalho (2005) entende que ocupar a mídia "torna-se a tarefa primordial da política de diferença, dando vazáo à luta das minorias no que ela tem de mais radical (no sentido de raiz): poder falar e ser ouvida" (BARBALHO, 2005, p.36). No contexto local, considera-se que o Portal Comunitário é o único site em Ponta Grossa/PR que tem a característica de mídia comunitária, em que os agentes sáo participativos a partir do seu envolvimento na produçáo, sugestấo de pautas e angulaçáo da reportagem, atuando não apenas como receptores de conteúdo. Lacerda (2002, p. 30) diz que "na mídia comunitária os membros da comunidade estáo presentes nas duas extremidades: a comunidade que emite a mensagem é a mesma que recebe".

Na nova geração em rede, "os movimentos sociais e organizaçóes não-governamentais buscam a visibilidade midiática como maneira de pressionar governos, partidos políticos 
e o mercado em relaçáo à agenda social global" (LACERDA, 2002, p.91-92). A reflexáo do autor vai ao encontro da tentativa de compreender qual a importância da prestaçấo de serviço realizada em diversos espaços no Portal Comunitário, tanto na seção Espaço Jurídico, que visa sanar dúvidas das comunidades relacionadas a diversas temáticas dos direitos sociais e coletivos, quanto na publicaçáo de reportagens sobre as entidades, em abordagens que vão dos problemas na infraestrutura do município aos campeonatos de bairro, bazares e eventos.

Amarildo Carnicel (2008, p.31) diz que:

É preciso enaltecer os fatos positivos, as realizaçóes da comunidade e valorizar pessoas por seus atos e talentos. É permitir que anônimos ganhem espaço na vitrine e passem a ser reconhecidos pela comunidade. É dar visibilidade a fatos e pessoas que tenham significado, importância e representatividade na comunidade.

Para compreender melhor os vínculos estabelecidos entre as entidades e as equipes do Portal Comunitário, deve-se passar por algumas classificaçóes de comunidade. Para Peruzzo (2002), um dos conceitos trata de "agrupamentos sociais situados em espaços geográficos de proporçôes limitadas (bairro, vila, lugarejo)". Além disso, consideramse ainda os grupos de interesses afins em interconexôes nas redes online, chamadas de "comunidades virtuais". No Portal Comunitário, busca-se trabalhar simultaneamente nas perspectivas de interação online e off-line, uma vez que o conceito de comunidade se amplia para abarcar a diversidade de lutas e formas de organizaçáo social, o que demanda estratégias e açôes diferenciadas para fortalecer a participação e garantir identificação com as produçóes jornalísticas.

Peruzzo (2010) propóe uma distinção em categorias na caracterização dos conceitos de comunicação popular, alternativa e comunitária. Ao nos orientarmos na perspectiva de classificação da autora, torna-se possível identificar o trabalho do Portal Comunitário como uma forma de comunicação popular-alternativa, assim caracterizada:

Processos de comunicação constituídos por iniciativas que envolvem a participação de segmentos populares, mas não respondem ou são assumidos pela comunidade como um todo. Em geral, são motivados ou viabilizados por ONG's, projetos de universidade, igrejas, etc. [...] Tende a se confundir com a comunicação comunitária em decorrência de similaridades, ou mesmo vir a constituir-se como tal. (PERUZZO, 2010, p. 29)

No que se refere a essa característica, percebe-se um interesse das fontes e movimentos em repercutir os conteúdos em suas redes de contato, além de manter as produçóes como material de arquivo, uma vez que se identificam e se reconhecem nas reportagens. Há, assim, uma proximidade entre jornalista e fonte que caracteriza o diálogo e a participação no jornalismo comunitário. Para garantir a regularidade deste diálogo, pelo menos uma vez por semana há o contato direto entre a equipe de produção e a comunidade, o que cria na comunidade local um canal de interaçáo na proposiçáo de pautas, na diversificação das fontes e na abordagem dos conteúdos jornalísticos. 


\section{Interaçáo e participaçáo no Espaço Jurídico do Portal Comunitário}

Há tempos o acesso à justiça tem sido objeto de análise no campo jurídico. Desde Mauro Cappelletti e Bryant Garth (2002), busca-se identificar o sentido da expressáo acesso à justiça como corolário de um estado de direito comprometido com a efetivaçáo dos direitos fundamentais.

Se nas duas primeiras ondas Cappelletti e Garth referiam ao acesso ao poder judiciário e à defesa de interesses supraindividuais, é na terceira onda que os autores firmam o acesso à informação como expressão do direito fundamental de acesso à justiça.

E é nesse sentido que o Portal Comunitário expressa sua atuaçáo. A seçáo Espaço Jurídico tem se mostrado um canal efetivo de interaçáo e informação de direitos trabalhistas e previdenciários dos cidadáos ponta-grossenses. A divulgaçấo de temas de relevo e o atendimento aos questionamentos de leitores direcionados a temas jurídicos têm feito do Portal Comunitário uma referência no tocante ao acesso à justiça.

A seçáa Espaço Jurídico, em proximidade com os princípios da comunicaçáo comunitária, recebe perguntas de cidadãos, orienta sobre dúvidas da comunidade e indica os assuntos que ganham destaque no Portal, do ponto de vista jurídico. Assim, busca fortalecer o diálogo com as entidades atendidas pelo projeto, além de levantar temas importantes e chamar a atençáo para temas de relevância social que estáo em pauta no momento.

No presente artigo, serão apresentados alguns elementos sobre a experiência do Espaço Jurídico no Portal Comunitário, de modo a refletir sobre a participação da comunidade e sobre a necessidade de oferecer orientaçóes que permitam um maior acesso e compreensão a respeito de temas jurídicos, em sintonia com as demandas sociais e com as práticas de cidadania.

Observa-se que as respostas apresentadas pelos advogados repercutem no conteúdo do site através de novas perguntas e comentários de leitores sobre os temas. Este princípio de participação é também a base da cobertura jornalística do Portal Comunitário. Além disso, a seção Espaço Jurídico busca levantar assuntos atuais para debate, dando visibilidade a questóes de interesse dos cidadáos.

$\mathrm{Na}$ Tabela 1, observa-se que, entre as maiores dúvidas dos leitores, estáo questôes trabalhistas. Este fato pode ser constatado pelo número de comentários nos artigos "Direito dos trabalhadores: fique por dentro" e "Horas extras, compensaçăo e banco de horas: conheça os direitos dos trabalhadores", com 29 e 30 comentários cada um. Mas, no número de visualizaçôes, o texto referente a horas extras tem o maior índice: 9.713 visualizaçóes desde sua publicação, em abril de 2012.

As pautas dos textos seguintes, como por exemplo do artigo "O portador e a portadora de deficiência física e seus direitos", postado em fevereiro de 2014, surge a partir dos comentários dos leitores no site. A equipe do Portal repassa aos colaboradores do projeto, responsáveis pela seção, que elaboram o texto com o objetivo de esclarecer o internauta sobre o assunto. 
Tabela 1. Análise de comentários e visualizaçóes do Espaço Jurídico

\begin{tabular}{l|c|c}
\hline Textos & Comentários & Visualizaçóes \\
\hline O portador e a portadora de deficiência física e seus direitos & 0 & 332 \\
\hline Livre acesso ao Judiciário & 1 & 645 \\
\hline Direitos dos trabalhadores: fique por dentro & 29 & 2.554 \\
\hline $\begin{array}{l}\text { Horas extras, compensaçáo e banco de horas: conheça os direitos dos } \\
\text { trabalhadores }\end{array}$ & 30 & 9.713 \\
\hline Benefício de Prestação Continuada: um direito do cidadão & 0 & 1.788 \\
\hline As greves, do ponto de vista dos trabalhadores. Você não faria? & 1 & 2.120 \\
\hline
\end{tabular}

Desde seu surgimento, há um grande número de acessos e comentários dentro do espaço. Isso se dá porque cada questão coletiva remete também a situaçóes individuais, em especial no que se refere aos direitos dos trabalhadores. Um exemplo é o comentário de um internauta na reportagem do Banco de Horas: "Boa noite, na empresa onde trabalho, em meses festivos, tem o costume de mandar a gente passar do horário normal, mas eles não pagam horas extras e não e dizem que nós somos obrigados. Só que nós trabalhamos 3 horas a mais do nosso horário e o sábado não tem dois horários sempre temos que abrir a loja e fechála. E nunca paga horas extra. Isso é certo?"

No caso de as perguntas estarem concentradas no artigo referente às dúvidas dos leitores, fica mais fácil encaminhar uma resposta ao internauta. Assim, cria-se um vínculo e um caráter de prestaçáo de serviços para a comunidade, uma vez que os comentários sáo abertos e não há nenhum custo para o oferecimento destas informaçóes.

Desde 2011, ano de surgimento do Espaço, foram 308 comentários publicados em todo site durante o período de 2011 até 2014. No ano de 2015, o espaço foi interrompido e não foi possível quantificar as informaçóes. Desse total, 103 comentários estáo relacionados a algum dos artigos descritos na Tabela 1, que se refere a $33,45 \%$ dos comentários.

E entre os 103 comentários relacionados a algum assunto publicado na tabela anterior, 61 estão publicados na seção Espaço Jurídico. Assim, percebe-se que um terço dos comentários tem caráter de prestaçáo de serviço e acesso à informaçáo, o que comprova o caráter do Portal como não apenas um meio de divulgação, mas de diálogo efetivo com a comunidade.

Em sintonia com os princípios da comunicação comunitária, considera-se a importância de manter um espaço de apoio jurídico no Portal Comunitário, em que se verifica a oportunidade de oferecer orientaçôes aos usuários do site e tratar de forma didática os temas jurídicos, contribuindo assim para o fortalecimento de práticas de cidadania.

\section{Consideraçóes Finais}

Com a análise do trabalho realizado ao longo da trajetória do Portal Comunitário, considera-se que o veículo apresenta potencial de alcance em diferentes grupos e entidades que participam do projeto, o que revela que a internet representa um importante espaço que pode estar a serviço da sociedade civil. Este aspecto pode ser constatado na produçấo jornalística comprometida com as demandas locais, no nível de participaçáo das pessoas 
nos diferentes espaços do site, no oferecimento de informaçóes úteis aos leitores do Portal e na preocupação em trabalhar os recursos do jornalismo on-line em sintonia com os interesses dos grupos, comunidades e entidades.

Registrar esta experiência, mais do que tornar pública uma iniciativa de produção em jornalismo comunitário realizada no âmbito da Universidade, constitui um esforço de refletir sobre os limites e a potencialidade do projeto, indicando caminhos que podem ser traçados para fortalecer a participaçáo cidadá e ampliar o alcance das açôes em comunicação comunitária.

Desse modo, entende-se que o Portal Comunitário, ao oferecer informaçóes e orientaçôes de interesse público, em linguagem acessível, contribui para o fortalecimento do caráter interativo e comunitário do projeto, auxiliando as pessoas no reconhecimento e na conquista de seus direitos e incentivando a prática cidadã. Trata-se, portanto, de uma história ainda recente, que assume sua importância no contexto das lutas da sociedade civil no contexto local.

\section{Referências}

BRAZ, Rodrigo Garcia Vieira. Direitos humanos fundamentais e direito à comunicação: entre a redistribuição e o reconhecimento. Revista Contemporânea, Rio de Janeiro, v. 9, n. 1 p. 60-77, 2011. Disponível em:

http://www.contemporanea.uerj.br/pdf/ed_17/contemporanea_n17_05_braz.pdf

CAPPELLETTI, Mauro; GARTH, Bryant. Acesso à Justiça. Porto Alegre: Sérgio Fabris Editora, 2002.

CARNICEL, Amarildo. Segmentação jornalística, jornal comunitário e cidadania. In: CARNICEL, Amarildo; FANTINATTI, Márcia (Orgs.). Comunicação e Cidadania: possibilidades e interpretações. Campinas: CMU publicações, 2008, p. 31.

GOBBI, Maria Cristina. Da ideologia ao pragmatismo: a Carta de São Bernardo. In: MARQUES DE MELO, José; GOBBI, Maria Cristina; SATHLER, Luciano (Orgs.). Mídia cidadã, utopia brasileira. São Bernardo do Campo: Universidade Metodista de São Paulo, 2006. p. 231247.

LACERDA, Juciano de Souza. A internet na gestão dos movimentos sociais. Estudo de caso das estratégias discursivas da Rede Brasileira de Comunicadores Solidários à Criança. In: PERUZZO, Cicilia K.; COGO, Denise; KAPLÚN, Gabriel. Comunicação e Movimentos Populares: Quais redes? São Leopoldo: Ed. Unisinos - Universidade do Vale do Rio dos Sinos, 2002, p.30; p.91-92.

MAIA, Rousiley; CASTRO, Maria Céres Pimenta Spínola (Orgs.). Mídia, esfera pública e identidades coletivas. Belo Horizonte: UFMG, 2006.

MAIA, Rousiley. Redes cívicas e internet: efeitos democráticos do associativismo. In: GOMES, Wilson; MAIA, Rousiley. Comunicação e democracia: problemas \& perspectivas. São Paulo: Paulus, 2008. 
MATTELART, Armand. A construção social do direito à Comunicação como parte integrante dos direitos humanos. Revista Brasileira de Ciências da Comunicação, São Paulo: Intercom, v. 32, n.1, p. 33-50, jan./ jun. 2009.

MORAES, Denis de. Comunicação alternativa, redes virtuais e ativismo: avanços e dilemas. Revista Eletrónica Internacional de Economía Política de las Tecnologías de la Información y la Comunicación (Eptic), v.IX, n. 2, mayo-ago/2007. Disponível em: http://www.seer.ufs.br/index.php/eptic/article/view/226/224.

PAIVA, Raquel. 0 espírito comum: comunidade, mídia e globalismo. Petrópolis: Vozes, 1998.

PERUZZO, Cicília M. Krohling. Comunidades em tempo de redes. In: PERUZZO, Cicilia K.; COGO, Denise; KAPLÚN, Gabriel. Comunicação e Movimentos Populares: Quais redes? São Leopoldo: Ed. Unisinos Universidade do Vale do Rio dos Sinos, 2002, p. 276-277.

PERUZZO, Cicília M. Krohling. Comunicação nos movimentos populares. 3. ed. Petrópolis: Vozes, $2004 a$.

PERUZZO, Cicília M. Krohling. Direito à comunicação comunitária, participação popular e cidadania. In: OLIVEIRA, Maria José da Costa (Org.). Comunicação pública. Campinas: Editora Alínea, 2004b, p. 49-79.

PERUZZO, Cicília M. Krohling. Aproximações entre comunicação popular e comunitária e a imprensa alternativa no Brasil na era do ciberespaço. In: BARBALHO, Alexandre; FUSER, Bruno; COGO, Denise (Org.). Comunicação Para a Cidadania: Temas e Aportes Teórico-Metodológicos. Intercom, 2010, p. 29.

SANTOS, Gustavo Ferreira. Direito fundamental à comunicação e princípio democrático. In: CONGRESSO NACIONAL DO CONPEDI, XV., 2006, Manaus. Anais... Florianópolis: Fundação Boiteux, 2006. Disponível em: http://www.conpedi.org.br/manaus/arquivos/anais/XIVCongresso/046.pdf 